\title{
Characterization of different blue cheeses using a custom-design multispectral imager
}

\author{
Asylbek KulmYrzaeV $^{1 *}$, Dominique BerTRAND ${ }^{2}$, Éric Dufour $^{1}$ \\ ${ }^{1}$ Unité de Recherches Typicité des Produits Alimentaires, ENITA Clermont-Ferrand, Marmilhat, \\ BP 35, 63370 Lempdes, France \\ ${ }^{2}$ Unité de Sensiométrie et de Chimiométrie, ENITIAA-INRA, BP 82225, 44322 Nantes, France
}

\begin{abstract}
The present study was conducted to determine whether multispectral imagery combined with chemometrics could accurately distinguish and classify different blue cheeses. The images of the pre-packed PDO Bleu d'Auvergne $(n=12)$ and Fourme d'Ambert $(n=23)$ blue cheeses were acquired using a custom-design multispectral imager. The image acquisition was conducted in the ultraviolet $(360 \mathrm{~nm}, 370 \mathrm{~nm}$ and $400 \mathrm{~nm})$, visible $(470 \mathrm{~nm}, 568 \mathrm{~nm}$ and $625 \mathrm{~nm})$ and nearinfrared $(875 \mathrm{~nm}$ and $950 \mathrm{~nm})$ spectral regions. The spectral functions of image texture based on the Fourier spectrum and image weights were extracted from the raw multivariate images using an image processing tool and a method of simultaneous decomposition of covariance matrices, respectively. Principal component analysis (PCA) and partial least squares discriminant analysis (PLSDA) of the spectrum functions showed a reliable discrimination of the Bleu d'Auvergne and Fourme d'Ambert blue cheeses. Examination of the image weights using PLSDA allowed the prediction of the producers of the blue cheeses. Our data demonstrated the ability of the multispectral imagery combined with chemometrics to characterize the quality and identity of the blue cheeses in a rapid and inexpensive manner.
\end{abstract}

blue cheese / characterization / multispectral imagery / image texture / chemometrics

\begin{abstract}
摘要 - 利用特制的多谱段成像仪描述蓝纹干酪的性质。本研究目的是为了确定是否可以 用多谱段图像结合化学统计学来准确识别和分类不同的蓝纹干酪。使用自行设计的多谱段 成像仪对预先包装好的原产地保护产品 Bleu d'Auvergne 干酪 $(n=12)$ 和 Fourme d'Ambert 干酪 $(n=23)$ 在紫外光 $(360 \mathrm{~nm} 、 370 \mathrm{~nm} 、 400 \mathrm{~nm})$, 可见光 $(470 \mathrm{~nm} 、 568 \mathrm{~nm} 、 625 \mathrm{~nm})$ 和近 红外光 $(875 \mathrm{~nm}$ 和 $950 \mathrm{~nm}$ ) 光谱区域分别采集图像。基于傅立叶光谱和图像权重而建立的 图像纹理光谱函数是从经图像处理工具和同步分解协方差矩阵方法处理的原始多元图像中 推算出来的。频谱函数主成分分析 (PCA) 和偏最小二乘判别分析 (PLSDA) 结果显示, 该方 法能可靠的区分 Bleu d'Auvergne 和 Fourme d'Ambert 蓝纹干酪。而且使用 PLSDA 检验图 像权重还能预测蓝纹干酪的生产商。实验表明, 多谱段图像结合化学统计学方法是一种快 速、经济的描述蓝纹干酪特性和鉴定蓝纹干酪的方法。
\end{abstract}

蓝纹干酪 / 特征 / 多谱段图像 / 图像纹理 / 化学统计学

Résumé - Caractérisation de différents fromages à pâte persillée par imagerie multispectrale. Cette étude avait pour objectif de déterminer le potentiel de l'imagerie multi-spectrale couplée à la chimiométrie, à discriminer et à classer correctement des fromages à pâte persillée. Les images de portions de fromages AOC Bleu d'Auvergne $(n=12)$ et Fourme d'Ambert

*Corresponding author (通讯作者): kulmyrzaev@yandex.ru 
$(n=23)$ pré-emballés ont été enregistrées au moyen d'un banc d'imagerie multi-spectrale développé par nos laboratoires. Les images ont été acquises sur une plage spectrale incluant l'ultraviolet $(360,370$ et $400 \mathrm{~nm})$, le visible $(470,568$ et $625 \mathrm{~nm})$ et le proche infrarouge $(875$ et $950 \mathrm{~nm})$. Les fonctions spectrales issues de transformées de Fourier et caractérisant la texture de l'image et les poids des images ont été extraites des images multi-spectrales au moyen, respectivement, d'un algorithme d'analyse d'image et d'une méthode de décomposition simultanée des matrices de covariances. L'analyse en composantes principales (ACP) et l'analyse discriminante par partial least squares (AD-PLS) des fonctions spectrales mettent en évidence une bonne discrimination des fromages Bleu d'Auvergne des Fourme d'Ambert. L'analyse de la matrice de données sur les poids des images par AD-PLS permet de prédire le producteur des fromages. Nos résultats montrent le potentiel de l'imagerie multi-spectrale couplée à la chimiométrie pour caractériser la qualité et l'identité de fromages à pâte persillée de manière rapide et peu coûteuse.

fromage à pâte persillée / caractérisation / imagerie multi-spectrale / texture des images / chimiométrie

\section{INTRODUCTION}

Continuously growing production of cheeses requires novel rapid and nondestructive analytical techniques to analyze quality and safety of cheeses. In addition to meeting compositional, flavor and aroma standards, cheese must also meet standards for body, texture, color and appearance. Control of origin of cheeses is also important so consumers can purchase authentic cheeses with confidence. Each sort of cheese has individual texture, color appearance, and formed as a result of a specific cheese-making technology. Consequently, these attributes are used to distinguish between great varieties of cheeses. It is a common practice when skilled experts evaluate quality and origin of cheeses. However, evaluation of cheese quality by a panel of experts is time-consuming and requires experienced specialists with specific knowledge and strong sensory capabilities. Therefore, this kind of cheese analysis is unsuitable for rapid and precise prediction of cheese quality on the industrial scale.

Fluorescence and infrared spectroscopies have been investigated extensively as rapid and nondestructive alternative techniques for the analysis of food properties and constituents [12]. Coupling spectroscopy with multivariate chemometric methods such as principal component analysis (PCA), partial least squares discriminant analysis (PLSDA), factorial discriminant analysis, common components and specific weights analysis (CCSWA), and others considerably increases the yield of useful information. This approach has been applied to studying melting temperature and content of solid fat in cream [4], protein structure and protein interaction during cheese ripening [15], measurement of milk composition $[17,18]$, effect of homogenization and heat treatment on the physicochemical properties and quality of milk [3, 13], cheese rheology [11], cheese identity and structure [6], and geographical origin of milk and cheeses $[9,10]$.

Classical spectroscopy yields information on a single point or small region of a sample at a time. A relatively new technology called multispectral imaging combines spectroscopic and imaging techniques to collect spectral and spatial information simultaneously. The data collected can be represented as a three-dimensional data cube, or images formed by adding two-dimensional spatial information to the one-dimensional spectral information at each pixel. Therefore, multispectral imaging dramatically increases the amount of usable information content. Imaging technology and image analysis have successfully been used to study muscles and have been proposed as an effective on-line 
technique for monitoring the quality of beef and pork [7,8,14,16].

A large number of cheeses (Roquefort, Stilton, Gorgonzola, Fourme d'Ambert, Bleu d'Auvergne, Cabrales, etc.) are grouped under the category of blue cheeses. All blue cheeses share the same flavor-producing agent, the mould Penicillium roquefortii. Despite similarities, the blue cheeses exhibit differences, i.e. origin of the milk (cow's, ewe's), shape of cheeses, strains of the Penicillium roquefortii, and color of the blue veins. Fourme d'Ambert and Bleu d'Auvergne are Protected Designation of Origin (PDO) cheeses both produced from cow's milk to a limited extent in Auvergne (France). PDO is a guarantee for consumers of the uniqueness of a food product, particularly cheeses, and an effective marketing tool for the producers. To guarantee the authenticity of the PDO cheeses, it is necessary to develop analytical techniques to enable authorities and producers to control correct description and labeling of cheeses.

This paper presents a study on the ability of the multispectral imaging technique to characterize different pre-packed blue cheeses, particularly Fourme d'Ambert and Bleu d'Auvergne. Combining multispectral imaging with multivariate statistical tools allowed differentiation of the cheeses depending on the cheese type and cheese producer.

\section{MATERIALS AND METHODS}

\subsection{Cheese collection}

Pre-packed pieces of 12 Bleu d'Auvergne and 23 Fourme d'Ambert blue cheeses were obtained from different supermarkets in Clermont-Ferrand and Nantes (France). The dairy companies manufacturing the blue cheeses were identified for the majority of the samples from product labels. In order to prove the ability of the technique to distinguish cheeses depending on cheese producer, 3 to 9 slices were cut off from one cheese and each slice was analyzed as an independent sample. The Fourme d'Ambert cheeses were manufactured by three different dairy companies, coded A $(n=24)$, $\mathrm{B}(n=6)$ and $\mathrm{C}(n=18)$. The manufacturers of three Bleu d'Auvergne cheeses were identified and coded A $(n=6)$, $\mathrm{B}(n=9)$ and $\mathrm{C}(n=19)$. The producers of several Bleu d'Auvergne cheeses were not identified from the product labels and therefore these samples were considered as "Supplementary" and coded S $(n=10)$. All cheeses were stored at $4{ }^{\circ} \mathrm{C}$ before conducting experiments.

\subsection{Multispectral imaging}

Cheese images were recorded using a custom-design multispectral imaging system presented elsewhere [1]. Briefly, the imaging system consisted of a dark enclosure with a sample holder. The dark enclosure was built as a box with a round opening on the top, through which the camera was mounted facing downwards. The illumination source of the system was also mounted in the dark enclosure and consisted of 8 sets of light-emitting diodes (LED) (Roithner LaserTechnik $\mathrm{GmbH}$, Vienna, Austria) emitting light in the ultraviolet $(360 \mathrm{~nm}, 370 \mathrm{~nm}$ and $400 \mathrm{~nm})$, visible $(470 \mathrm{~nm}, 568 \mathrm{~nm}$ and $625 \mathrm{~nm})$ and near-infrared (875 $\mathrm{nm}$ and $950 \mathrm{~nm})$ spectral ranges. The images of the cheese samples were captured with a highly sensitive cooled CCD color camera (DX20, KAPPA Opto Electronics, Gleichen, Germany) with a zoom lens (focal length of 5.6$32 \mathrm{~mm}$, COMPUTAR, Bioblock, Illkirch, France) and a Peltier air-cooling system. The imaging system was connected to a PC and controlled by a custom design frame-acquiring program written in Matlab 7.5.0.342 (R2007b) (MathWorks, Natick, 


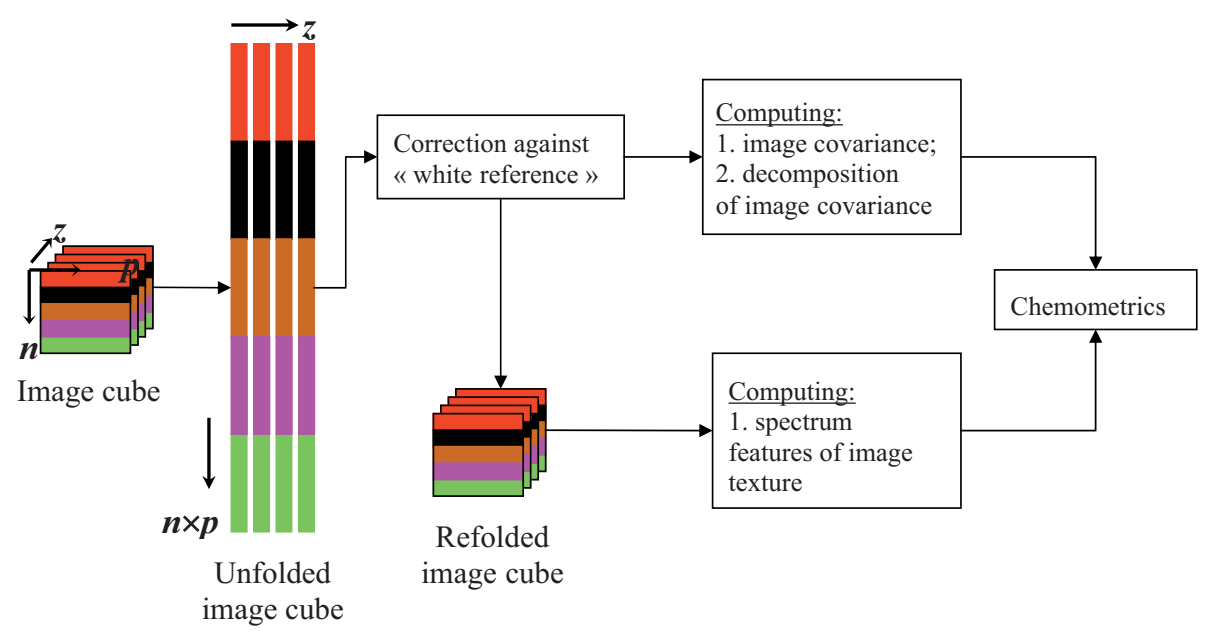

Figure 1. Procedures developed for image processing.

MA, USA). The imaged area of each sample was about $5 \times 4 \mathrm{~cm}$ and each image formed a matrix dimensioned $480 \times$ 660. Twenty-four images (8 illumination wavelength $\times 3$ (RGB) channels of the camera) corresponding to different spectral conditions were collected on each sample. Twenty-one images were selected for further analysis after removing three images containing no information.

\subsection{Image analysis}

Spectral images are multivariate and can be regarded as a three-way data structure, a 'cube'. They are interpreted as a stack of images or as one image of pixel vectors [2]. Considering pixels as vectors of spectral data independently of the spatial relationship occurring in the image scene is equivalent to unfolding each image into a single vector, i.e. unfolding the three-way multivariate image into a usual two-way data matrix (Fig. 1). The two-way data matrix is then much more convenient for mathematical treatment.

An image cube with two spatial ( $n=$ 480 pixels and $p=660$ pixels) and one wavelength dimension $(z=21$ channels $)$ was built using the images of each sample. The final cube images were then obtained as a logarithm of the ratio "white reference/image cube" (Fig. 1). This transformation was carried out for every pixel and every spectral condition.

In total, 141 image cubes were analyzed using two approaches.

First, spectral functions of image texture based on the Fourier spectrum were extracted for each channel of an image cube [5]. Extracted image spectral functions were expressed as the spectrum in polar coordinates applied to an image (Fig. 2) yielding a function $S(r, \theta)$, where $S$ is the spectrum function, and $r$ and $\theta$ are the radial and the angular coordinates, respectively. One-dimensional functions $S_{\theta}(r)$ for each $\theta$ and $S_{r}(\theta)$ for each $r$ were computed and a global description was obtained by these functions as [5]:

$$
S(r)=\sum_{\theta=0}^{\pi} S_{\theta}(r)
$$

and

$$
S(\theta)=\sum_{r=1}^{R_{0}} S_{r}(\theta)
$$




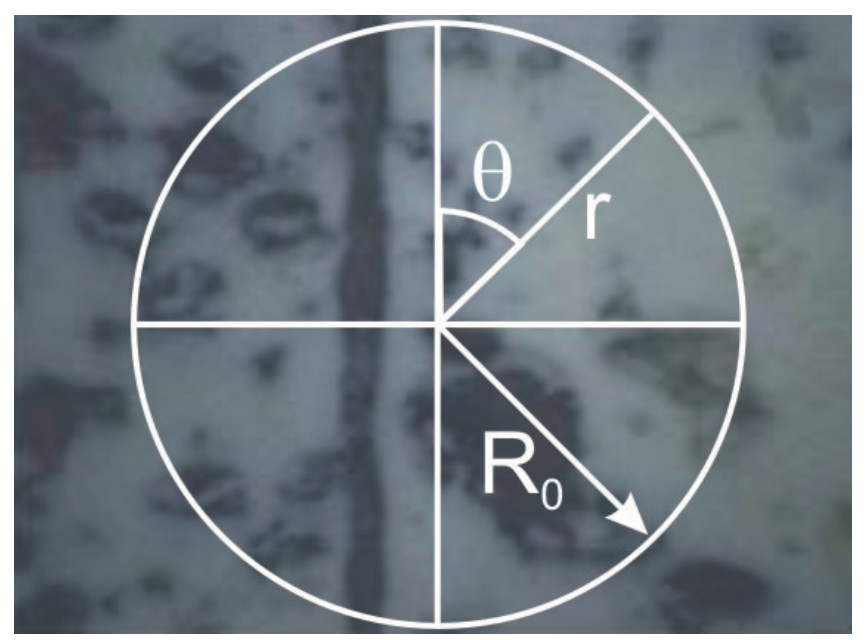

Figure 2. A coordinate system applied to the cheese images for computing the spectrum function $S(r, \theta)$ ( $r$ is the radial coordinate, $\theta$ is the angular coordinate, $R_{0}$ is the radius of a circle centered at the origin). The computation yields the 1-D functions $S_{\theta}(r)$ and $S_{r}(\theta)$.

where $R_{0}$ is the radius of a circle centered at the origin. Functions $S(r)$ and $S(\theta)$ constitute a spectral-energy description of texture for an image region under consideration. The idea behind this approach is that the behaviors of functions $S(r)$ and $S(\theta)$ differ from one image to another, which could make it possible to distinguish between the studied cheeses. The code "specxture" developed previously [5] was applied to computing the two preceding image texture measurements.

The second approach is based upon projecting the images into an appropriate factorial space, which is carried out using a method of simultaneous decomposition of covariance matrices. This method allows the extraction of components common to each image and reveals their specificities through specific weights. It is assumed that common loading vectors exist that can be weighted differently for each multivariate image [2]. Singular value decomposition (SVD) of $\mathbf{X}$, an unfolded image cube, is illustrated in Figure 3. $\mathbf{X}$ is obtained by unfolding the image cube $\underline{\mathbf{X}}$ and is then decomposed into score images $\mathbf{t}_{\boldsymbol{a}}$ and loading vectors $\mathbf{p}_{\boldsymbol{a}}$ using PCA (Fig. 3). In order to speed up computation, the cross-product matrix $\mathbf{X}^{\prime} \mathbf{X}$ is subjected to SVD. Thus, the model of decomposition is [2]:

$$
\mathrm{X}^{(k)^{\prime}} \mathrm{X}^{(k)}=\sum_{a=1}^{A} \lambda_{a}^{(k)} \mathrm{p}_{a} \mathrm{p}_{a}^{\prime}
$$

where $\mathbf{X}^{(k)}$ is the unfolded matrix derived from the $k^{\text {st }}$ image cube, $\mathbf{p}_{\boldsymbol{a}}$ is the loadings, and $\lambda_{a}^{(k)}$ is the specific weights of the latent dimension $a$ for the $k^{\text {st }}$ image cube. In the present study image weights were computed for 10 dimensions, which was assumed to provide reliable discrimination of the cheese samples.

The spectral functions of image texture and image weights were computed using algorithms programed in Matlab 7.5.0.342 (R2007b).

The image analysis results were organized into three matrices. The first one contained the values of $S_{\theta}(r)$ computed with the increment of $r$ equal to 1 pixel. The first column and the first row of this matrix 
A. Kulmyrzaev et al.

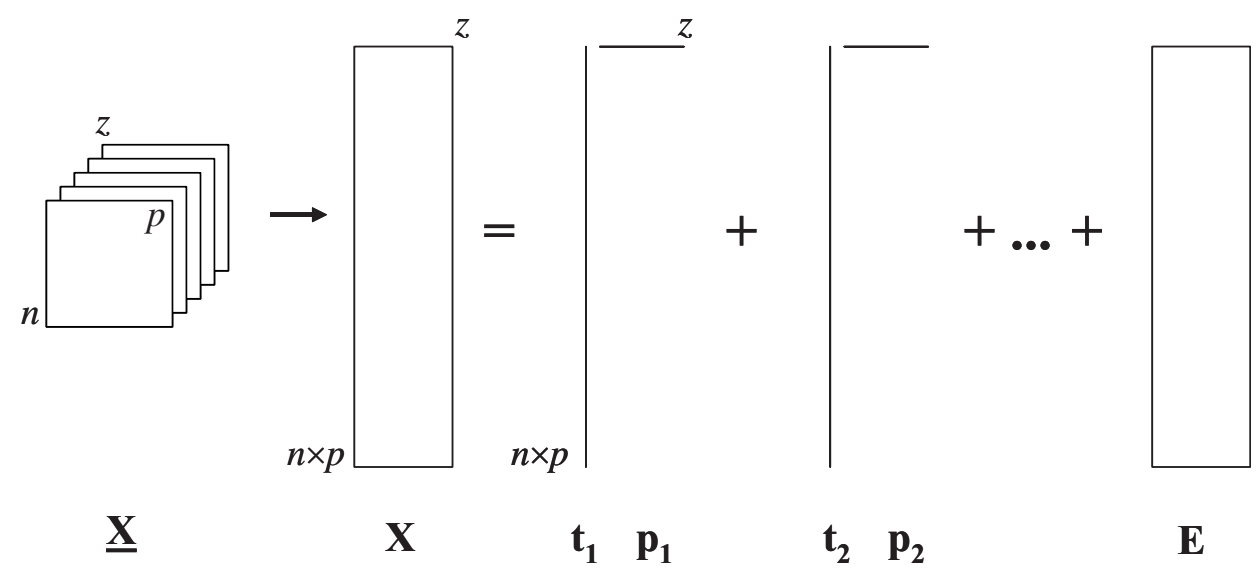

Figure 3. Singular value decomposition of an unfolded image ( $\underline{\mathbf{X}}$ is an image cube, $\mathbf{X}$ is an unfolded matrix, $\mathbf{t}_{\boldsymbol{a}}$ is score images, $\mathbf{p}_{\boldsymbol{a}}$ is loading vectors and $\mathbf{E}$ is the noise part of the decomposition).

contained cheese sample names and values of $r$, respectively. The structure of the second matrix was similar to that of the first one and contained the values of $S_{r}(\theta)$ computed with the increment of $\theta$ equal to $1^{\circ}$. The third matrix was built of the computed image weights $\lambda_{a}^{(k)}$, in which the first column represented the cheese sample names, while the first row represented the dimensions (10).

\subsection{Multivariate statistical analysis}

Principal component analysis (PCA) and partial least squares discriminant analysis (PLSDA) written by the authors were applied to the computed image features. The objective of the statistical processing was to derive relevant information from the image data allowing the discrimination and classification of the blue cheeses. In PLSDA a "leave-one-out" cross-validation process was used for validation, that is, leaving one sample of the calibration set at a time for prediction. The custom-design versions of PCA and PLSDA programed in
Matlab 7.5.0.342 (R2007b) were utilized in the statistical data treatment.

\section{RESULTS AND DISCUSSION}

\subsection{Analysis of spectrum features}

PCA and PLSDA of the spectrum features showed that the function $S_{\theta}(r)$ computed from images is more useful in discrimination of the blue cheeses than the function $S_{r}(\theta)$. When applying PCA to the function $S_{\theta}(r)$ it was possible to observe evident differences between the Bleu d'Auvergne and Fourme d'Ambert blue cheeses. Figure 4 shows a PCA scatterplot view of the Bleu d'Auvergne and Fourme d'Ambert blue cheeses in respect to their scores in the first two principal components (PC1 and PC2). The image patterns (e.g., shapes of blue veining) of the two cheeses are very similar, which makes it difficult to differentiate between the cheeses visually. The results of PCA demonstrated that spectral features of the images are appropriate indicators for differentiation of blue cheeses. As shown in 


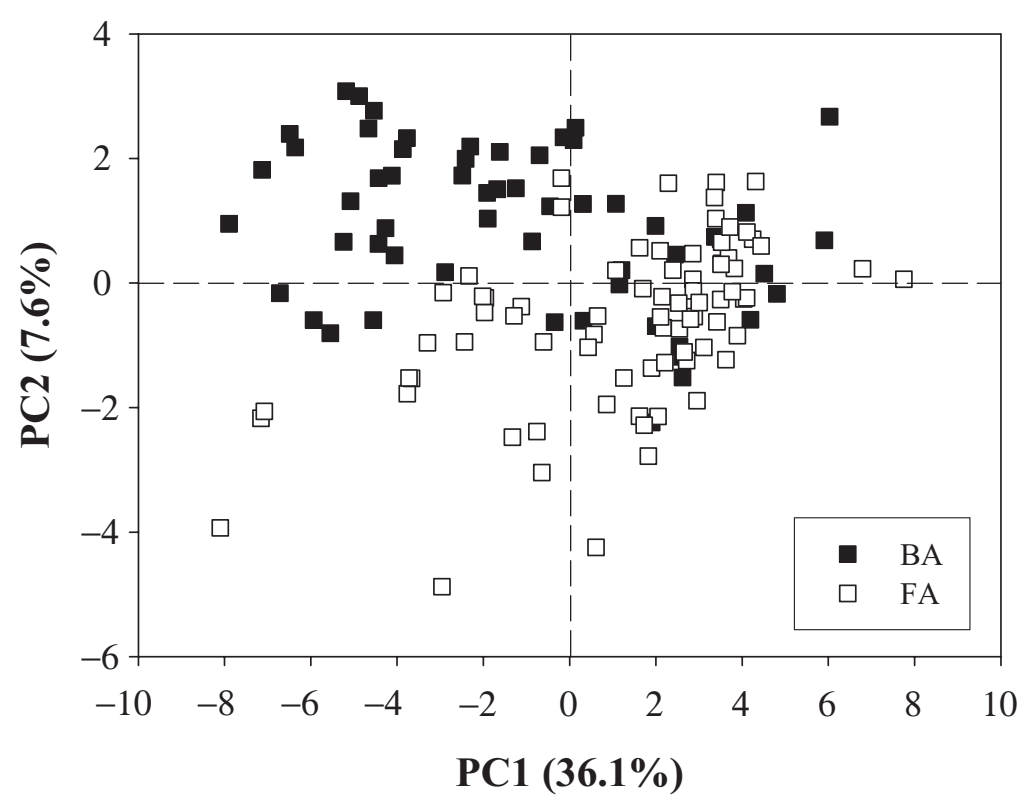

Figure 4. Discrimination of the blue cheeses using PCA applied to the spectrum function $S_{\theta}(r)$ (BA is the Bleu d'Auvergne blue cheeses and FA is the Fourme d'Ambert blue cheeses).

Figure 4, despite some samples of the Bleu d'Auvergne and Fourme d'Ambert blue cheeses overlapping, two separate groups of the cheeses can be easily distinguished.

Figure 5 shows a score plot of a PLSDA classification of the Bleu d'Auvergne and Fourme d'Ambert blue cheeses based on the function $S_{\theta}(r)$ computed from the cheese images. The PLSDA model took into account five variables. Most of the Bleu d'Auvergne cheeses were assigned positive scores regarding dimension D1, while the majority of the Fourme d'Ambert cheeses were scored negative. Cheese samples were classified according to the group for which they had the best match. This can be expressed in terms of the percentage of the samples assigned to the correct class. The classification success of the cheeses is presented in Table I.

Since the source of information for the identification of cheeses was the function $S_{\theta}(r)$, which characterizes the behavior of the spectrum along the radial direction on an image, it was assumed that this information should be of spectral origin. In order to verify this hypothesis, the function $S_{\theta}(r)$ for the cheese samples was analyzed. In Figure 6 an example plot of $S_{\theta}(r)$ in the 30 pixels distance from the origin along the radial direction computed for a Bleu d'Auvergne blue cheese and a Fourme d'Ambert blue cheese is presented. These two cheese samples marked with circles in Figure 5 are in opposition to each other, which points out considerable difference in the texture of the corresponding images. The difference between these two cheeses can be characterized by the notable shift of the corresponding peaks in the functions $S_{\theta}(r)$ (Fig. 6). Thus, it can be concluded that the classification of the Bleu d'Auvergne and Fourme d'Ambert blue cheeses derived using PCA (Fig. 4) and PLSDA (Fig. 5) is based upon the spectral features of the cheese images. 


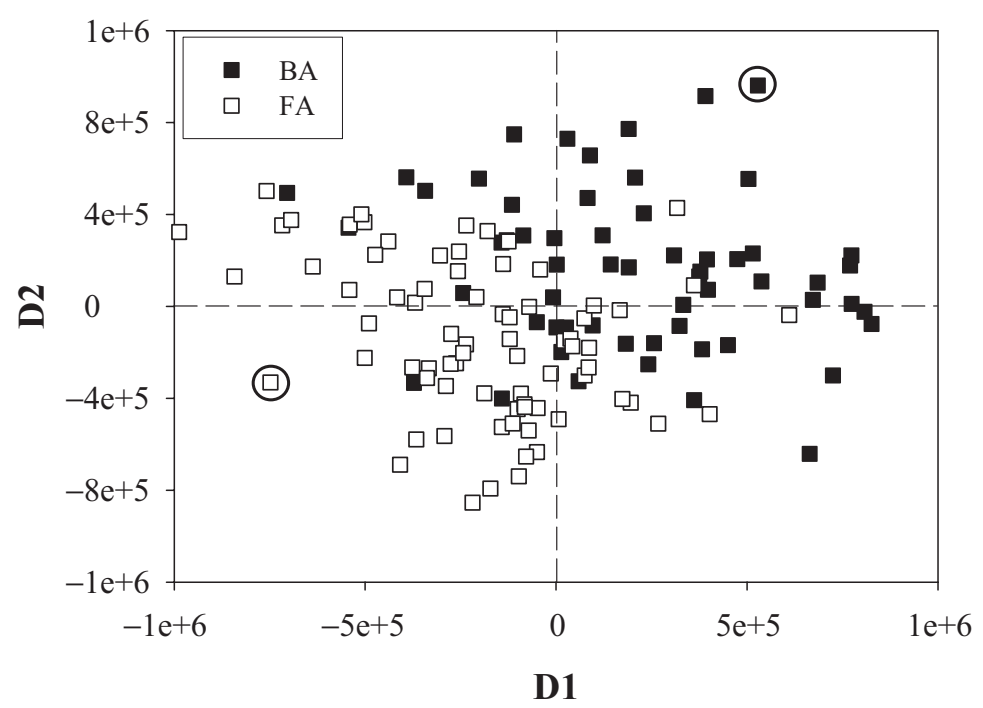

Figure 5. Score plot of the classification of the blue cheeses resulting from PLSDA applied to the spectrum function $S_{\theta}(r)$ (BA is the Bleu d'Auvergne blue cheeses and FA is the Fourme d'Ambert blue cheeses).

Table I. Results of the PLSDA classification of the blue cheeses obtained using the spectral measurements of the cheese image texture.

\begin{tabular}{lccc}
\hline & Bleu d'Auvergne & Fourme d'Ambert & Classification success (\%) \\
\hline Bleu d'Auvergne & 61 & 3 & 95.3 \\
\hline Fourme d'Ambert & 8 & 69 & 89.6 \\
\hline
\end{tabular}

\subsection{Analysis of cheese image weights}

It was intended to analyze whether the image weights could be a reliable indicator to distinguish between the blue cheeses according to the cheese producer. Initially, the image weights $\lambda_{a}^{(k)}$ were projected in the space determined by the first and second latent variables, which were more present in the multivariate images compared with other latent variables. The discrimination of the cheeses observed on this kind of plot was poor (data not shown). Therefore, in order to distinguish the cheeses better, it was decided to analyze the image weights data table by means of PLSDA. It should be noted that the best results were obtained when PLSDA was performed separately on the Bleu d'Auvergne and Fourme d'Ambert blue cheese image weights. Figure 7 presents a factorial map determined by the first and second dimensions produced by the PLSDA applied to the image weights of the Bleu d'Auvergne cheeses. It can be seen that the cheeses from the producer coded $\mathrm{C}$ were widely separated from the rest, and there was some overlap of the cheeses produced by the A and B cheesemakers and supplementary $\mathrm{S}$ cheeses (unknown producer). All the $\mathrm{C}$ cheeses had 


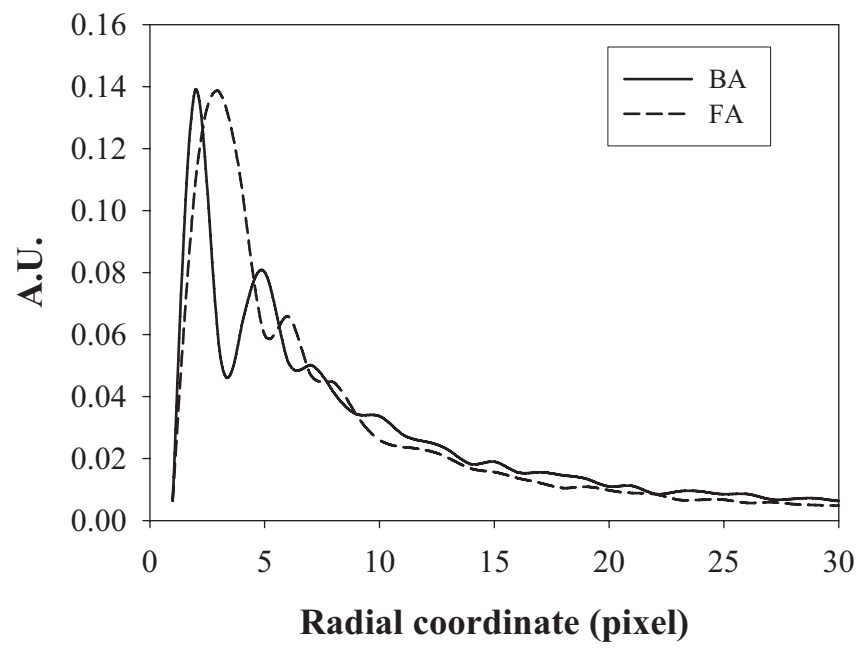

Figure 6. Examples of the spectrum function $S_{\theta}(r)$ computed for the Bleu d'Auvergne cheese (BA) and Fourme d'Ambert cheese (FA) marked with circles in Figure 4.

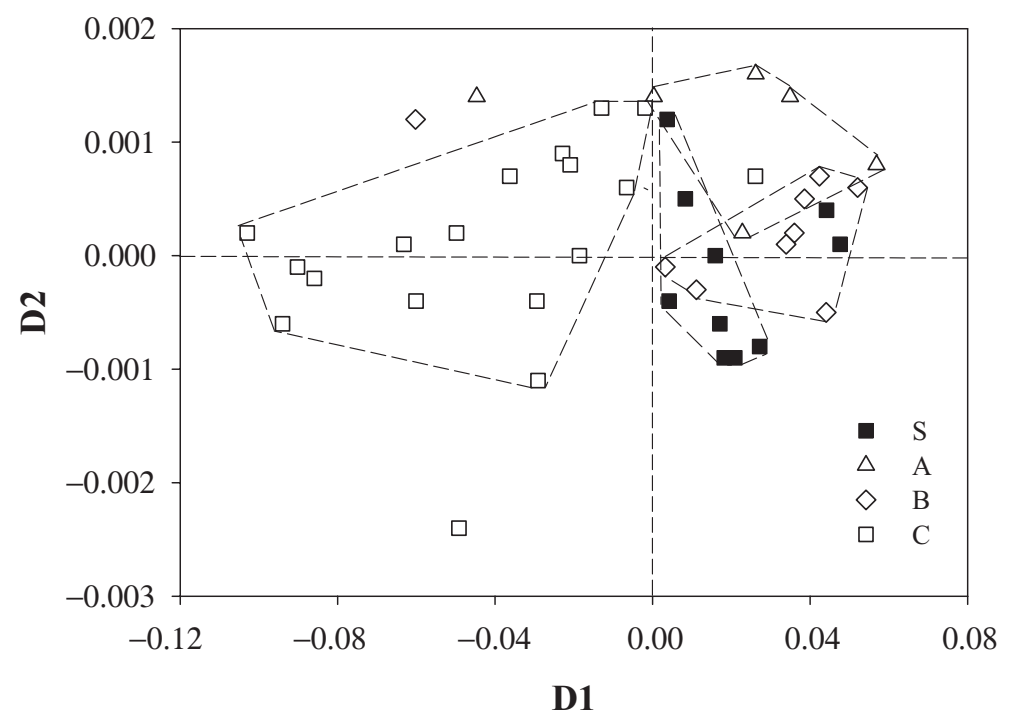

Figure 7. Discrimination of the Bleu d'Auvergne blue cheeses according to the cheese producer, resulting from PLSDA of the image weights (A, B, C and S denote different cheese producers). 
Table II. Results of the PLSDA classification of the Bleu d'Auvergne blue cheeses according to the cheese producer obtained using the image weights (A, B, C and S denote different cheese producers; see Materials and Methods).

\begin{tabular}{cccccc}
\hline & A & B & C & S & Classification success (\%) \\
\hline A & 4 & 2 & 0 & 0 & 66.7 \\
B & 2 & 6 & 0 & 1 & 66.7 \\
C & 2 & 0 & 15 & 1 & 83.3 \\
S & 1 & 5 & 0 & 12 & 66.7 \\
\hline
\end{tabular}

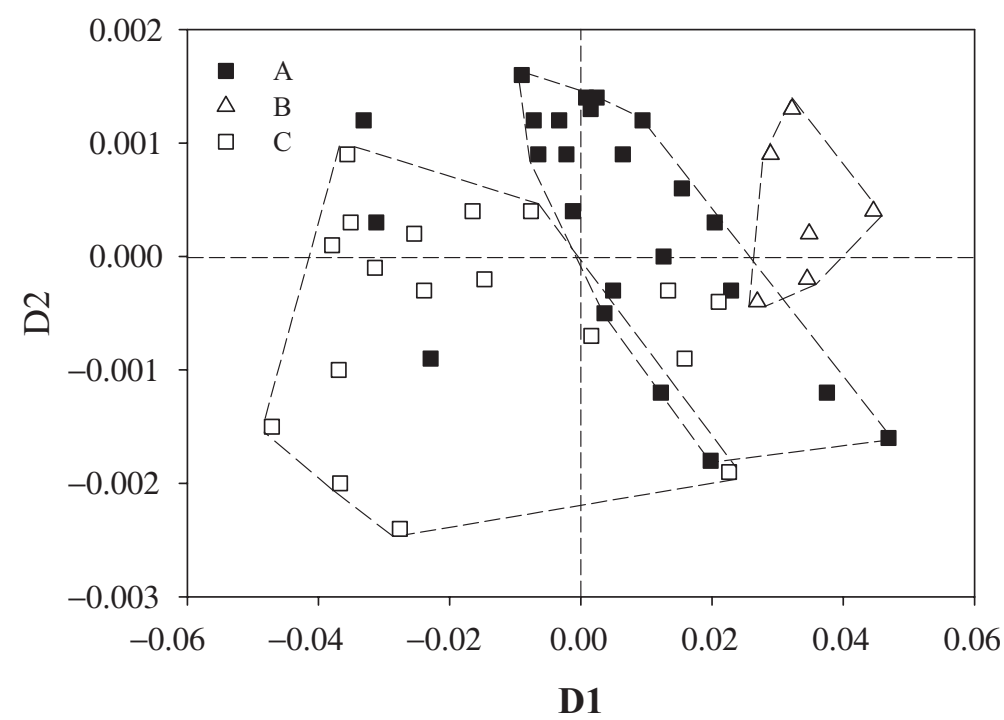

Figure 8. Discrimination of the Fourme d'Ambert blue cheeses according to the cheese producer, resulting from PLSDA of the image weights (A, B and C denote different cheese producers).

negative scores according to the first dimension (D1), while the A, B and S cheeses had positive scores, meaning the image features of the $\mathrm{C}$ cheeses differed to a considerable extent from those of the remaining cheeses (Fig. 7). The image patterns such as shapes and sizes of blue veining and pixel intensities observed on the blue cheese pieces are greatly influenced by the cheese-making conditions. The distribution of the cheeses observed in Figure 7 might suggest that the production conditions of the cheeses coded A, B and $\mathrm{S}$ were similar. The accuracy of classification of the Bleu d'Auvergne cheeses by means of PLSDA, considering a model with 5 dimensions, is presented in Table II. The best performance was obtained for the $\mathrm{C}$ cheeses $(83.3 \%$ ), and the A, B and $\mathrm{S}$ cheeses were predicted with lower accuracy $(66.7 \%)$. The data in Table II prove that the A, B and S cheeses were characterized with more homogeneous image weights, which caused more problematic classification.

Better performance was demonstrated for the Fourme d'Ambert blue cheese differentiation and classification. In Figure 8, the cheeses were well separated into three groups according to the dimension D1 in 
Table III. Results of the PLSDA classification of the Fourme d'Ambert blue cheeses obtained using the image weights (A, B and C denote different cheese producers; see Materials and Methods).

\begin{tabular}{ccccc}
\hline & A & B & C & Classification success (\%) \\
\hline A & 16 & 4 & 4 & 66.7 \\
B & 0 & 6 & 0 & 100 \\
C & 4 & 1 & 13 & 72.2 \\
\hline
\end{tabular}

relation to three producers, $\mathrm{A}, \mathrm{B}$ and $\mathrm{C}$. Cheeses A, B and $\mathrm{C}$ were classified as accurately as $66.7 \%, 100 \%$ and $72.2 \%$, respectively (Tab. III). Good classification of the Fourme d'Ambert blue cheeses indicated the greater difference in their image patterns, which could be the effect of production conditions, i.e. the contribution of native microflora from the local milk and environment to the cheese ripening, differing from one producer to another.

Consequently, results from PLSDA revealed that image weights could be an effective indicator to differentiate the blue cheeses with respect to the production origin.

\section{CONCLUSION}

Application of chemometric tools to analyzing multivariate images obtained by means of the simple multispectral imager offers an effective tool for distinguishing and classifying different blue cheeses. As the present study has demonstrated, the advantage of multispectral imaging in cheese quality studies is that by applying a large number of illuminating light wavelengths specific to different cheese constituents it is possible to obtain multivariate images containing useful information for identification of the blue cheeses. An important point in the multivariate image processing is extraction of appropriate image features, which contain information of interest. Spectral measurements of image texture based on the Fourier spectrum and expressed as the spectrum function in polar coordinates, $S(r, \theta)$ (Fig. 2), were shown to be a good image feature to distinguish between the Bleu d'Auvergne and Fourme d'Ambert blue cheeses. This result was yielded when the spectrum function was analyzed using PCA and PLSDA. On the other hand, the image weights derived using the method of simultaneous decomposition of covariance matrices applied to the unfolded image cube (Fig. 3) and submitted to the PLSDA procedure allowed the discrimination of the blue cheeses by the cheese producer. In summary, this study demonstrated the capacity of multispectral imagery to classify different blue cheeses in spite of the visual similarity of their structure and appearance. It is reasonable to expect that as an analytical technique, multispectral imagery combined with chemometrics will offer a rapid and relatively inexpensive method for monitoring cheese quality and identity.

Acknowledgements: The financial contribution of the European Commission to this project is acknowledged (Project MIF1-CT2005-021890).

\section{REFERENCES}

[1] Chevallier S., Bertrand D., Kohler A., Courcoux P., Application of PLS-DA in multivariate image analysis, J. Chemometr. 20 (2006) 1-9.

[2] Courcoux P., Devaux M.F., Bouchet B., Simultaneous decomposition of multivariate images using three-way data analysis. Application to the comparison of cereal grains by confocal laser scanning 
microscopy, Chemometr. Intell. Lab. Syst. 62 (2002) 103-113.

[3] Dufour E., Riaublanc A., Potentiality of spectroscopic methods for the characterization of dairy products. I. Front-face fluorescence study of raw, heated, and homogenised milks, Lait 77 (1997) 657-670.

[4] Dufour E., Riaublanc A., Potentiality of spectroscopic methods for the characterization of dairy products. II. Mid infrared study of the melting temperature of cream triacylglycerols and of the solid fat content in cream, Lait 77 (1997) 671-681.

[5] Gonzalez R.C., Woods R.E., Eddins S.L., Digital Image Processing Using Matlab, Pearson Prentice Hall, Upper Saddle River, NJ, USA, 2004.

[6] Herbert S., Mouhous Riou N., Devaux M.F., Riaublanc A., Bouchet B., Gallant D.J., Dufour E., Monitoring the identity and the structure of soft cheeses by fluorescence spectroscopy, Lait 80 (2000) 621-634.

[7] Jun Q., Ngadi M., Wang N., Gunenc A., Monroy M., Gariepy C., Prasher S., Pork quality classification using a hyperspectral imaging system and neural network, Int. J. Food Eng. 3 (2007) Article 6 (available at: http://www.bepress.com/ijfe/vol3/iss1/art6).

[8] Karnuah A.B., Moriya K., Nakanishi N., Nade T., Mitsuhashi T., Sasaki Y., Computer image analysis for prediction of carcass composition from cross-sections of Japanese Black steers, J. Anim. Sci. 79 (2001) 28512856.

[9] Karoui R., Bosset J.-O., Mazerolles G., Kulmyrzaev A., Dufour E., Monitoring the geographic origin of both experimental French Jura hard cheeses and Swiss Gruyère and l'Evitaz PDO cheeses using mid-infrared and fluorescence spectroscopies: a preliminary investigation, Int. Dairy J. 15 (2005) 275-286.

[10] Karoui R., Martin B., Dufour E., Potentiality of front-face fluorescence spectroscopy to determine the geographic origin of milks from the Haute-Loire department (France), Lait 85 (2005) 223-226.

[11] Kulmyrzaev A.A., Dufour E., Noel Y., Hanafi M., Karoui R., Qannari E.M., Mazerolles G., Investigation at the molecular level of soft cheese quality and ripening by infrared and fluorescence spectroscopies and chemometrics-relationships with rheological properties, Int. Dairy J. 15 (2005) 669-678.

[12] Kulmyrzaev A.A., Karoui R., De Baerdemaeker J., Dufour E., Infrared and fluorescence spectroscopic techniques for the determination of nutritional constituents in foods, Int. J. Food Prop. 10 (2007) 299-320.

[13] Kulmyrzaev A.A., Levieux D., Dufour E., Front-face fluorescence spectroscopy allows the characterization of mild heat treatments applied to milk. Relations with the denaturation of milk proteins, J. Agric. Food Chem. 53 (2005) 502-507.

[14] Li J., Tan J., Martz F.A., Heymann H., Image texture features as indicators of beef tenderness, Meat Sci. 53 (1999) 17-22.

[15] Mazerolles G., Devaux M.F., Duboz G., Duployer M.H., Mouhous Riou N., Dufour E., Infrared and fluorescence spectroscopy for monitoring protein structure and interaction changes during cheese ripening, Lait 81 (2001) 509-527.

[16] Shackelford S.D., Wheeler T.L., Koohmaraie M., Coupling of image analysis and tenderness classification to simultaneously evaluate carcass cutability, longissimus area, subprimal cut weights, and tenderness of beef, J. Anim. Sci. 76 (1998) 2631-2640.

[17] Tsenkova R., Atanassova S., Itoh K., Ozaki Y., Toyoda K., Near infrared spectroscopy for biomonitoring: cow milk composition measurement in a spectral region from 1100 to 2400 nanometers, J. Anim. Sci. 78 (2000) 515-522.

[18] Tsenkova R., Atanassova S., Toyoda K., Ozaki Y., Itoh K., Fearn T., Near-infrared spectroscopy for dairy management: measurement of unhomogenized milk composition, J. Dairy Sci. 82 (1999) 2344-2351. 